\title{
El palacio ubetense del siglo XVI. Entre la tradición medieval y la renovación clasicista
}

\author{
ARSENio MoREno Mendoza \\ Profesor Titular, Universidad Pablo de Olavide (Sevilla). Historia del Arte
}

\begin{abstract}
RESUMEN
La evolución tipológica del palacio ubetense del Renacimiento no responde a una lógica evolutiva acorde con la implantación, cada vez más creciente, de los nuevos lenguajes clasicistas. La pervivencia de elementos que responden a una tradición mudéjar, o el arraigo de constantes arquitectónicas medievales, son factores que conviven, en algunos casos, con planteamientos de una modernidad conceptual y lingüística sorprendente. De este modo, junto a la persistencia de elementos morfológicos miméticos y codificados, podemos advertir la presencia continuada del modelo de alcázar urbano, dotado de torre-mirador, cuya existencia responde a valores simbólicos señoriales, así como a una rotunda vocación de establecer una clara jerarquización visual en un tejido urbano de configuración medieval.
\end{abstract}

\begin{abstract}
The typological evolution of Renaissance palaces in Ubeda (Jaén, Spain) does not respond to an evolutive logic following the more and more introduced new classicistic languages.

The survival of elements that respond to a Mudejar tradition or the influence of architectural medieval constant features are factors that, in some cases, live together in conceptual modernity and surprising linguistics. Thus, together with the persistence of mimetic morphological elements, the continuous presence of an urban fortress model can be noticed. This model is provided with a lookout tower, whose existence respond to both symbolic noble values and to a categorical wish to establish a clear visual hierarchy in a medieval-structured urbam fabric.
\end{abstract}




\section{LA CASA DE LAS TORRES Y LOS ORIGENES DE LA ARQUITECTURA PALACIEGA EN ÚBEDA.}

La primera gran construcción palaciega ubetense del siglo XVı es la llamada Casa de las Torres.

Desconocemos la fecha del inicio de sus obras, aunque ya en 1544, cuando su propietario y promotor el capitán don Andrés Dávalos de la Cueva extiende escritura de mayorazgo, enumerando los bienes vinculados de su propiedad, nos dice lo siguiente:

"...Primeramente, unas casas principales que nos habemos y tenemos en la dicha ciudad de Úbeda en la Plazuela de San Lorenzo con todo lo anexo y junto de ella que es toda isla con todo lo que en ella labraremos y edificaremos» 1 .

De esta información podemos deducir algunas cuestiones: En primer lugar que para 1544 el palacio aún no había sido concluido del todo. La segunda, que su propietario disponía de toda una gran manzana para llevar a cabo una edificación ais-

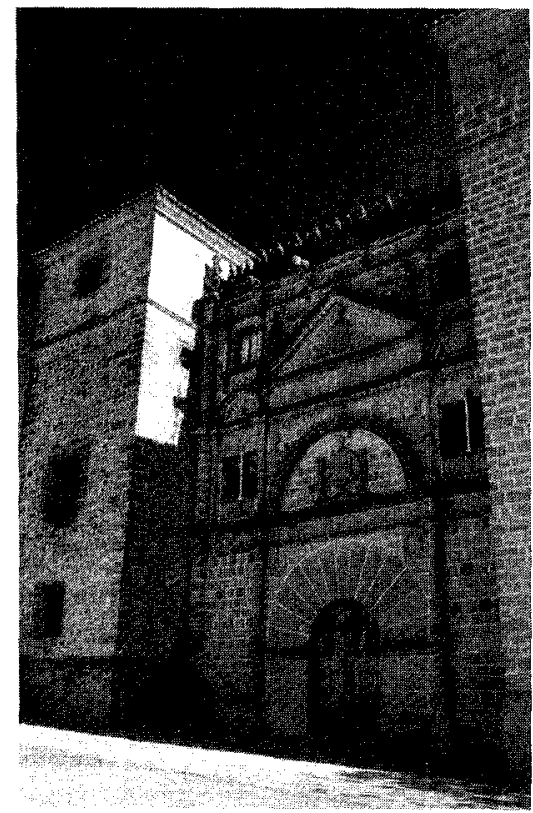

Fig. 1. Casa de las Torres. Fachada.

\footnotetext{
${ }^{1}$ Moreno Mendoza, A.: Úbeda renacentista. Madrid: Electa, 1993, pág. 108.
} 
lada, algo muy importante en el colmatado parcelario de una collación como San Lorenzo

De su inquilino apenas si disponemos de algunas noticias biográficas. Sabemos, por ejemplo, que estaba casado con doña Antonia de Orozco, miembro de otro rancio linaje local; también que era hijo de Rodrigo Dávalos, quien tuvo que litigar con el Concejo de la Ciudad en 1532 para obtener sentencia favorable sobre su inclusión en el padrón de la nobleza, algo que nos llama la atención pues sus antepasados ya figuraban en la sentencia Albitraria como fijosdalgos notorios ${ }^{2}$.

Andrés Dávalos, regidor de la ciudad, había sido admitido como comendador en la aristocrática Orden de Santiago, ocupando más tarde cargos administrativos con la Corona tales como el de corregidor de Murcia y Guadix ${ }^{3}$.

Si parcos son los datos que disponemos sobre su promotor, más exiguas son las noticias sobre el proceso edilicio de esta mansión. Ignoramos quién fue su tracista, como también desconocemos los canteros que intervinieron en sus obras, $o$ la cronología de las mismas, dada la ausencia de protocolos notariales en las primeras décadas del siglo.

Sólo, a tenor de un elemental análisis estilístico, podemos deducir que su torreada fachada, con su correspondiente crujía, debió ser anterior - algo por lo demás habitual en cualquier proceso constructivo palatino- al cuerpo central que conforma su hermoso patio, "mucho más refinado e italiano» - en palabras de Chueca Goitia-4.

Este patio, de planta cuadrada, presenta organización de doble galeria, con arcos de medio punto levemente levantados. Sus columnas ofrecen un módulo esbelto, casi frágil. Es el llamado «módulo andaluz», tal como lo definiera Chueca. Si a ello le añadimos el uso de un doble ábaco, su reminiscencia mudejar se hace más evidente.

La presencia de mármoles italianos en Andalucía, introducidos entre 1533 y 1535, fue extraordinariamente masiva, hasta el extremo que para una sola ciudad como Sevilla algunos autores, como Gestoso, han calculado en torno a $30.000-$ cifra a todas luces excesiva - las columnas adquiridas por sus moradores a lo largo del siglo xvı. Nada tiene, por tanto, de extrañarnos que existiera un verdadero “módulo andalusi», un modelo de fuste de excepcional esbeltez que habría de traspasar nuestras fronteras llegando incluso a Marruecos. En efecto, sabemos

2 Toral Peñaranda, E.: Úbeda (1542-1510). Jaén: Instituto de estudios Giennenses, 1975, pág. 341.

3 BARRANCO Delgado, J.: «Tras de nuestras piedras almeras. La Casa de las Torres». Ibiut, Año VIII, num. 42.

${ }^{4}$ Chueca Goitia, F.: Arquitectura del siglo xVI. Ars Hispaniae, t. XI, Madrid, 1953, pág. 202. 
como el soberano marroquí d'Ahmed el-Mançûr, a imitación de nuestros palacios, hacia 1580 hace importar desde Pisa, a través del puerto de Livorno, los mármoles para su residencia de Badie en Marrakech ${ }^{5}$, incorporando en aquellas latitudes un Renacimiento de claras resonancias mudéjares.

Estamos hablando, por tanto, de un Renacimiento autónomo y experimentalista, subsidiario de los nuevos lenguajes italianos, pero que gusta de conservar sus propios códigos emanadas de una tradición constructiva propia y secular.

La galería superior, con sus arquivoltas imbricadas, presenta en sus enjutas alternancia de escudos y clásicos tondos. Estos tondos, o clípeos, esculpidos en alto relieve, presentan un total de dieciséis bultos: toda una clásica galería de «uomini famosi», un magnífico repertorio «de claris mulieribus» $y$ «de viris ilustribus» ${ }^{6}$.

Contrasta la clásica diafanidad andaluza de este patio con la contundente opacidad de su fachada.

Ésta se abre a una pequeña plaza, posiblemente dispuesta al tiempo que el propio palacio, una practica que se iba abriendo camino en la morfología urbana del Quinientos en otras ciudades?

La gran fachada está enmarcada por dos grandes torres. Nos encontramos, por tanto, ante un prototipo palaciego de alcázar urbano, una arquitectura residencial fortificada por sendos baluartes de claras reminiscencias medievales.

Aunque en el imaginario literario renacentista de autores como Cristobal de Villalón o Montemayor ${ }^{8}$ la presencia de poderosos crocheles constituía todo un paradigma de nobleza y opulencia, es indudable que estos torreones quedaban más identificados con un tiempo pretérito de enfrentamientos partidarios, de luchas entre bandos enfrentados, características de una Baja Edad Media tan turbulenta como presente en la mentalidad de los nobiliarios linajes, que con un ideal cortesano de corte renacentista. La torre continuaba siendo para un patriciado urbano de origen militar un claro emblema de poder, un símbolo de prestigio nobiliario, y tal vez - como veremos más adelante- nunca dejó de estar presente en la constitución de nuestra arquitectura civil.

${ }^{5}$ KLAPISCH-Zuber, Cristiane: Les maîtres du marbre. Carrare 1300-1600. París: S.E.V.P.E.N., 1969, pág. 229.

${ }^{6}$ Moreno mendoza, A.: Op. cit., págs. 113-117.

7 El historiador Alonso de Morgado refiriéndose a la capital hispalense, afirma "que no hay caballero en Sevilla que no tenga una placeta frente a su casa". Similar opinión comparte para esta misma ciudad Rodrigo Caro al afirmar que estas plazas «desahogan, adornan, y descubren la magestad de los edificios». Cit. por R. L. Kagan, Ciudades del Siglo de Oro. Madrid: El Viso, 1986.

${ }^{8}$ Lampérez y Romea, V.: Arquitectura civil española de los siglos I al XVII. Tomo I. Edición facsimil. Madrid: Ediciones Giner, 1993, págs. 348-349. 


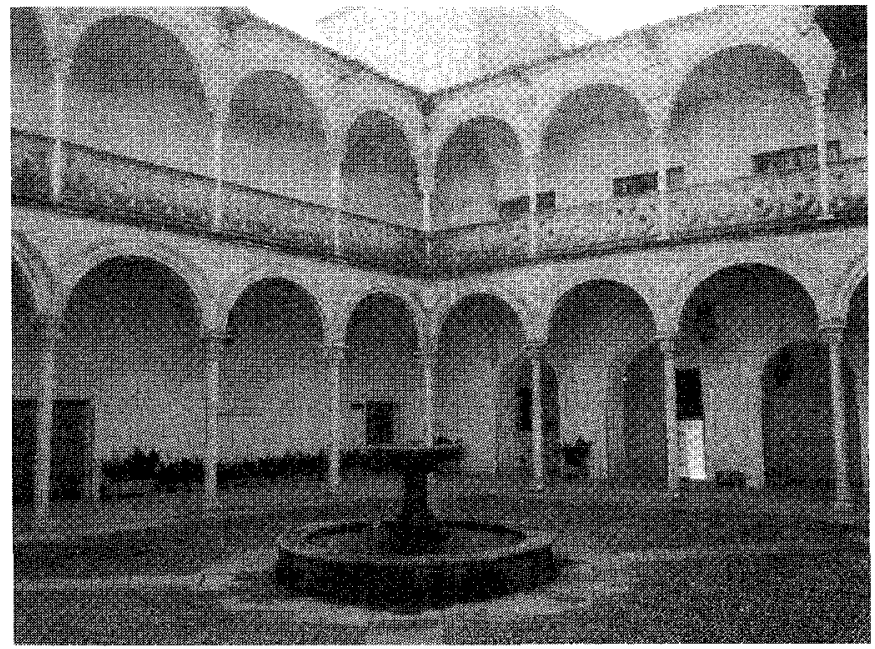

Fig. 2. Casa de las Torres. Patio.

Don Vicente Lampérez, a este respecto en 1922, se refería a la existencia de torres en la arquitectura palatina española como «un rasgo» nacional que, en realidad, no desaparecería hasta el siglo XVIII.

Lampérez, en su análisis histórico de la arquitectura civil española, considera estos elementos integrales como un importante medio defensivo, a la par que un modo de exteriorización de nobleza y poderío. Este autor llega a establecer un catálogo de tipologías, a tenor de la colocación de la misma en la fábrica palaciana, que va desde la torre única, enhiesta, dominando el palacio y el barrio, hasta la torre ampliamente abierta y profusamente ornamentada, pasando por la torre ubicada en un ángulo del edificio, o en dos o más, si el palacio estaba descubierto por todos sus lados.

Entre ambos torreones se despliega la enorme fachada de "paramento ornamentado» - diría el mismo Lampérez-. Una fachada-pantalla, o fachada-retablo (ajena a la estructura interna del edificio), que sigue una ordenación propia de otros modelos protorenacentistas propios del periodo Reyes Católicos, cuyos exponentes más significativos serian, entre otros, la fachada de la Universidad de Salamanca, o la de San Esteban en esta misma ciudad.

En su planta baja, sobre un lienzo macizo, se abre la gran puerta de acceso, con arco de medio punto sobre impostas y un marcado dovelaje castellano. En sus enjutas encontramos dos bustos en relieve enmarcados de laúreas. Este es, sin duda, un motivo ornamental habitual en el Renacimiento, pues se trata de imáge- 
nes apotropáicas, un elemento iconográfico tomado de Horapolo, cuya función simbólica es la defensa de la casa ${ }^{9}$.

Enmarca la portada dos columnas anilladas y estriadas en su parte inferior, con profusión de grutescos en los fustes. A ambos lados de estas, sobre gruesas ménsulas, se elevan dos nuevas medias columnas que, atravesando los restantes cuerpos de la fachada, contribuyen a conferir a la misma un marcado sentido de verticalidad.

Sobre el paramento de este primer cuerpo, al igual que los restantes, encontramos una abundante representación de conchas y veneras santiaguistas, en alusión a la condición de miembro de esta orden de su fundador.

El cuerpo se remata con un clásico entablamento de friso de grutescos, sobre el que se eleva un segundo, en cuyo eje central se levanta un frontón de vuelta redonda con decoración de rosetas en su intradós y «putti» entrelazados en la arquivolta que hacen sonar las trompetas de la Fama. En su tímpano, bajo celada y cimera, las armas de Dávalos y Orozco, sostenidas por las figuras encadenadas de dos salvajes, un elemento heráldico de amplia presencia en la arquitectura civil de las primeras décadas del siglo en la ciudad, del cual ya nos hemos referido en otras ocasiones ${ }^{10}$.

A ambos lados del frontis encontramos dos bíforas ventanas separadas por parteluz. La de la derecha está apeada sobre cornucopias, o cuernos de la abundancia enlazados, plasmación alegórica de la fortuna como compañera de la Virtud que nos muestra Alciato en su emblema CXVIII. La de la derecha, en cambio, descansa sobre águilas afrontadas, que no es otra cosa que la representación simbólica de la inmortalidad del alma que alcanza con su vuelo el cielo y, por extensión, alegoría de la inmortalidad del linaje ${ }^{11}$.

Estos vanos, coronados por veneras, están flanqueados por balaustres, un préstamo directo - podríamos decir- de la obra de Diego Sagredo.

Sobre un ligero entablamento se alza el tercer cuerpo de la fachada, compuesto por un gran frontis triangular peraltado sobre breves balaustres, que alberga en su tímpano las armas familiares. A ambos lados, siguiendo los ejes de verticalidad colaterales, encontramos sendas veneras, a modo de frontones superpuestos, con la efigie de Saritiago Peregrino en su izquierda y un busto femenino - no identificado- a la derecha. Tras éstos, dos nuevos vanos de arcos deprimidos, con columnas a ambos lados apeadas sobre mascarones.

9 Esteban LoRENTE, J. F:: Tratado de iconografía. Madrid: Istmo, 1991, pág. 189. Horapolo, jeroglífico núm. 24, «La protección».

10 Moreno Mendoza.: Úbeda..., págs. 110-111.

11 García Mogollon, F. J.: «La portada principal de la catedral de Coria. Primera aproximación a su estudio iconográfico". Cuadernos de Arte e lconografía, Tomo II, núm. 3, Madrid, 1989. 
Corona el cuerpo un gran friso corrido de grutescos y mascarones. Y sobre él, en un arrebatado criterio de acumulación, una gran cornisa volada sobre la que descansa una gran crestería de fuerte sabor gótico, a la que no ha de faltar sus gárgolas y tenantes.

No es intención de este trabajo detenerme más de lo imprescindible en el análisis de aspectos iconográficos y, si no he hecho hasta el momento, es para intentar evidenciar cómo una arquitectura de recio sabor medieval puede llevar implícita un rico repertorio de morfemas renacentistas, en muchos casos de un contenido semiótico plenamente humanista, sin que, por ello, naturalice orgánicamente su concepción.

\section{LA DECADA DE LOS TREINTA: EL PALACIO DE DON FRANCISCO DE LOS COBOS}

Parece ser que la primera construcción palaciega no fortificada, construida durante las tres primeras décadas del siglo en la comarca, es el Palacio de Jabalquinto de Baeza, otro bello ejemplar de síntesis estilística y temporal, donde su constructor ya introduce una galería de arcos de medio punto en la planta superior de su fachada.

Este palacio, mandado construir por don Juan Alfonso de Benavides, debe inscribirse dentro de un ámbito estilístico próximo a la arquitectura de un Juan Guas y, por tanto, dentro del lenguaje gótico-isabelino. Sin embargo, lo más interesante para nosotros - tal como ya señalara Marín de Terán- es su precocidad formulación a la hora de plantear su implantación urbana. Aquí ya nos encontramos ante un volumen edilicio exento, de composición cúbica, "que manifiesta su independencia respecto al tejido circundante por medio de unas alineaciones de fachadas que no se subordinan a las del viario del entorno", proclamando la singularidad y autosuficiencia de la edificación ${ }^{12}$.

La aparición plena de lenguajes renacentistas tendrá efecto en la ciudad en la década de los 30 .

De todas las edificaciones palaciegas iniciadas por estos años, tal vez, la más antigua sea el palacio mandado levantar por don Francisco de los Cobos.

El Comendador Mayor de León había heredado a la muerte de su padre en 1530 la vieja mansión solariega de la collación de Santo Tomás.

12 MARIN DE TERÁN, L.: «Las transformaciones urbanas en Úbeda y Baeza durante el siglo XV|». [En] Úbeda en el siglo XVI. Úbeda: El Olivo, 2002, pág. 173. 


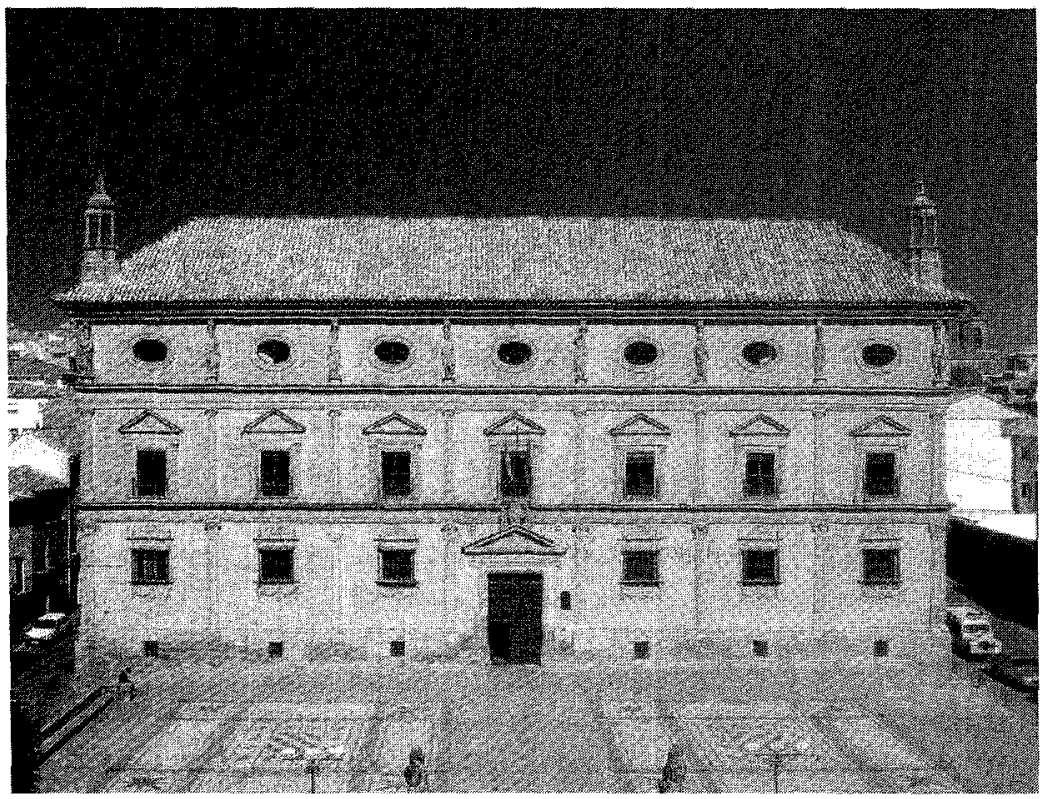

Fig. 3. Palacio Vázquez de Molina. Fachada.

En 1531, tras la adquisición de diversas fincas contiguas a la propiedad, el Concejo de Úbeda otorga a don Francisco una concesión de agua. Un año más tarde la construcción debe estar bastante avanzada, pues su hombre de confianza en la ciudad, don Fernando Ortega Salido, le hace enviar un "rasguño", o pequeño plano de la misma, junto a una extensa carta donde le da cuenta de los pormenores de la obra ${ }^{13}$.

La dirección de los trabajos había recaído en el arquitecto Luis de Vega, quien tras ordenar la demolición de las fincas compradas por Cobos - «las casas están en el suelo y de las piedras dellas se labran los çimientos del cuarto"-, respeta la primitiva casa familiar, limitándose sólo a diseñar un nuevo módulo residencial, unido a la anterior fábrica por unos espacios corridos cuya estructura, modestamente, nos recuerda en su configuración la disposición orgánica de los hospitales Reyes Católicos, luego aplicada a otros edificios posteriores como el toledano Hospital de Tavera.

${ }^{13}$ Archivo General de Simancas. Mapas, planos y dibujos, XXXVIII-83. Úbeda, 1 de agosto de 1532. Según diseño de Martín Ortega y Luis de Vega. A.G.S. Sección Estado, Leg. 25, fols. 234-237. 


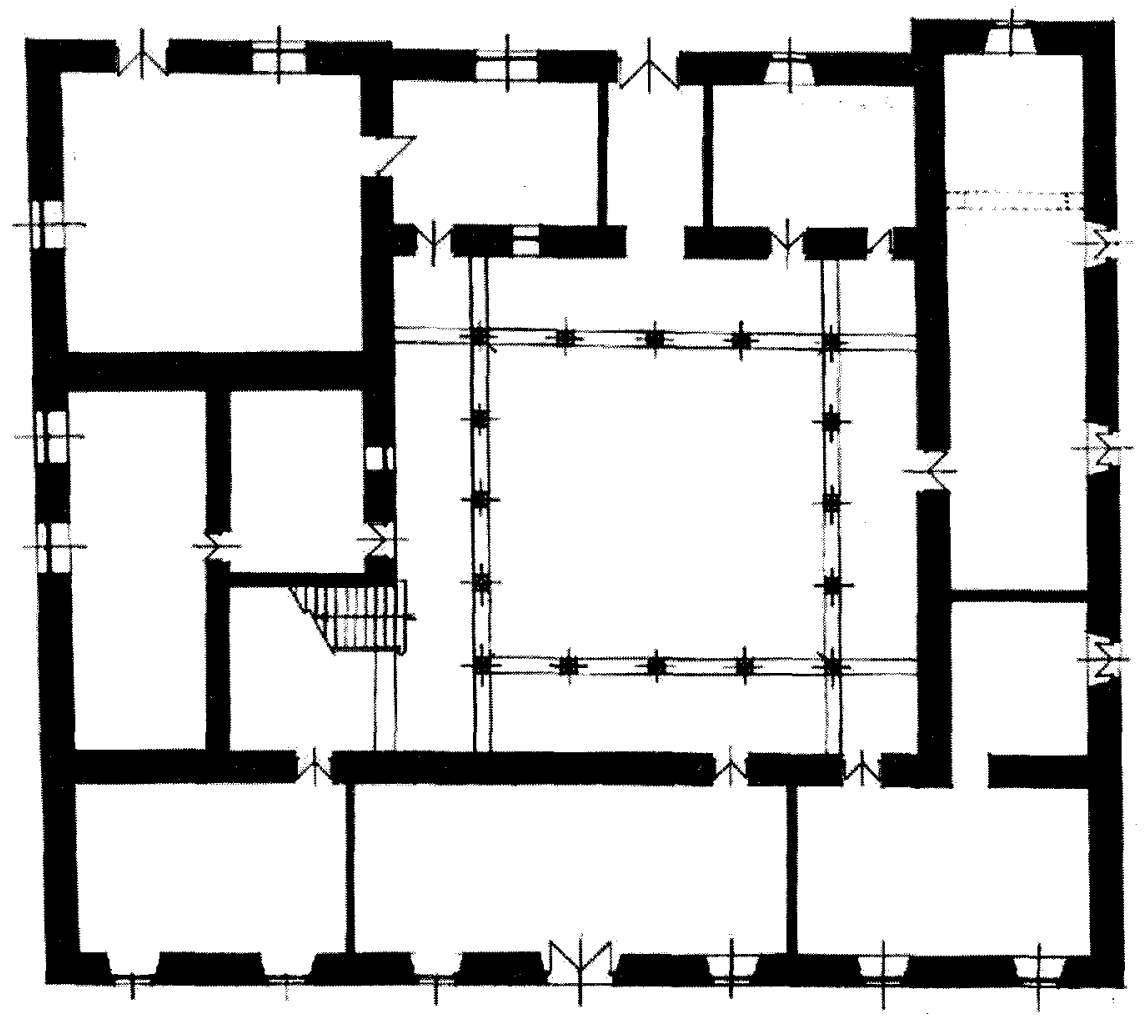

Fig. 4. Palacio Vázquez de Molina. Planta.

El primer cuerpo, o patio primitivo, sospechamos que quedaría reservado a los servicios más funcionales de la casa. El segundo, de nueva planta y doble galería (con arcos deprimidos en la superior), si que presenta un claro carácter «representativo», conformando el nuevo espacio emblemático de la mansión. En definitiva, se trataba de unir dos ámbitos, uno antiguo y otro nuevo, instalando en su vértice de confluencia una escalera claustral de gran desarrollo y estableciendo una crujía principal -donde quedaría albergado el zaguán- que es literalmente cerrada por una gran fachada a manera de pantalla.

El espacio resultante es el de un gran cuerpo modular, de concepción cúbica, aunque no exenta.

Empero, entre las propuestas iniciales que se barajan para la nueva edificación, su arquitecto, a través de la carta remitida por Ortega, ofrece a su promotor la 
posibilidad de construir una torre en la trasera de la casa, aunque esta no fuera demasiado elevada ${ }^{14}$, tal como dibuja Vega en el mencionado croquis.

Como podemos, pues, comprobar, aunque estemos ya hablando de un modelo constructivo renacentista, una propuesta de recomposición de corte albertiano, no se descarta la posibilidad de incluir en el mismo una reminiscencia medieval, como de hecho era la torre, con su doble función de mirador y baluarte.

En este sentido, de nuevo, Lampérez y Romea nos advertía cómo hay que tener presente que este prototipo de torre palatina, tanto como una remota génesis militar, tendría su posible origen en el «miradero de las casas moriscas»; algo exclusivo de la arquitectura civil aragonesa y andaluza.. "No es fácil - decía don Vicente-, en muchos casos, distinguir el origen militar o el civil de la torre urbana andaluza; acaso éste se marca en ser única, poco elevada, situada en un ángulo del edificio, muy abierta, con huecos, que velan celosías de madera, y estar cubierta con tejado piramidal, volado con alero sobre los muros, por contraste con la de origen militar, que, como he señalado, termina en cornisa y crestería, y se cubre en azotea» ${ }^{15}$.

\section{LA DECADA DE LOS CUARENTA Y LA PLENITUD CLASICISTA: LOS PALACIOS DEL DEAN ORTEGA Y DON JUAN VÁZQUEZ DE MOLINA}

Tendriamos que aguardar a la siguiente década para asistir en la ciudad a la plenitud de su arquitectura civil, con la aparición de un modelo de palacio de concepción cúbica y exenta, una construcción orgánica cuya estructura interna se proyecta en una fachada capaz de intervenir y ordenar el espacio urbano circundante.

Mediada la década de los cincuenta el palacio del DEÁN ORTEGA ya debería estar en una fase edilicia plenamente avanzada. Se está enlosando su planta baja y el carpintero Juán de Ocón se compromete a «hacer las puertas de las salas como Luis de Vega lo dejó ordenado" ${ }^{16}$.

Aunque en 1553 es proyectada la ampliación de su fachada oeste, al ocupar el antiguo solar de la pescadería, todo indica que su trazado debió realizarse en la anterior década en simultanea coincidencia con el palacio Vázquez de Molína.. También parece obvio atribuir estas trazas a Andrés de Valdelvira, sin descartar por otra parte- la presencia y un cierto asesoramiento por parte de Vega.

\footnotetext{
14 KenISTON, H.: Francisco de los Cobos. Secretario de Carlos V. Madrid: Castalia, 1980, pág. 146.

15 LAMPÉREZ: Op. cit., págs. 351-352.

16 Moreno Mendoza: Op. cit., pág. 125.
} 


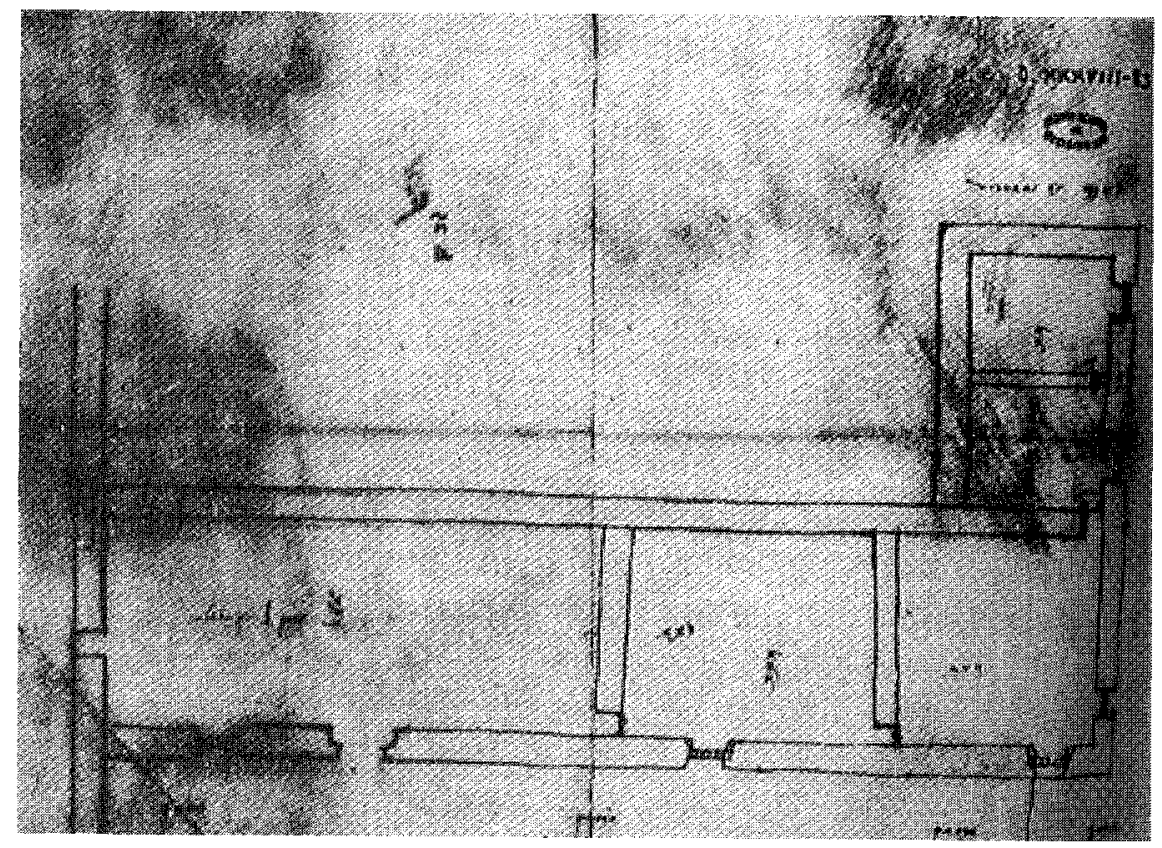

Fig. 5. Palacio de Francisco de los Cobos. Detalle de la planta. Martín Ortega y Luis de Vega. Archivo general de Simancas.

Este palacio se articula en torno a un patio central compuesto por doble galería de arcadas de medio punto. Resaltar que el módulo utilizado en los fustes de estas columnas es el más grácil y nazarita de todos los existentes en la ciudad.

De planta prácticamente rectangular, proyecta su exterior en dos fachadas en ángulo, mostrando una clara subordinación, un interesante diálogo, con el otro gran edificio de este «llano del Salvador»: La Sacra Capilla de El Salvador, de la que el deán de Málaga y capellán regio, don Francisco Ortega Salido, era su capellán mayor.

La fachada ofrece una clara disposición horizontal, no exenta de licencias decorativas como los frontones que rematan sus balcones o las grandes ovas de la cornisa, préstamos literales y caprichosos de la obra de Sebastián Serlio en su edición castellana.

Sin embargo la más importante y clasicista construcción palaciega de todo el Renacimiento ubetense y, posiblemente, una de las obras más interesantes de la arquitectura civil del renacimiento español, es el palacio mandado edificar por Juan VÁZQUEZ DE MOLÍNA, un sobrino educado con Cobos, que seguirá los pasos en la carrera política y administrativa de su tío. 


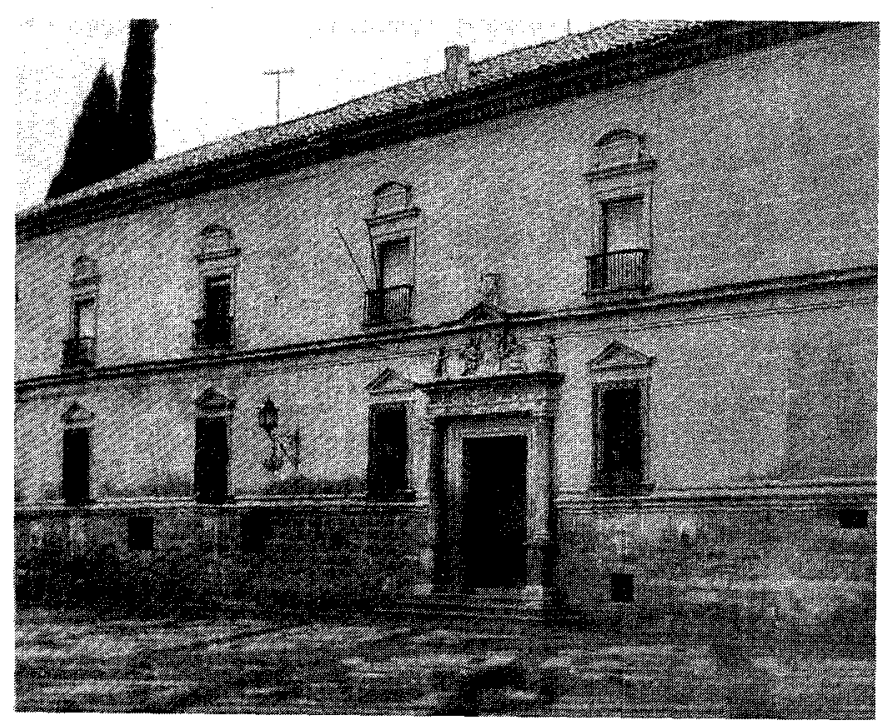

Fig. 6. Palacio de Deán Ortega. Fachada.

Este palacio estaba llamado a ordenar urbanisticamente el otro gran espacio de la gran plaza que lleva su nombre, imponiendo a la postre un nuevo eje de axialidad con la fachada de la iglesia colegial de Santa María de los Reales Alcázares.

Su cronología constructiva debe quedar establecida entre 1546, fecha del contrato protocolizado más antiguo de los encontrados, merced al cual eran encargados los trabajos de rejería de su fachada, y 1565, año en que Vandelvira, su tracista, efectúa la tasación de las labores de losadura. ${ }^{17}$ Empero, parece inevitable pensar que sus trazas originales debieron ser ejecutadas con anterioridad, en una fecha no muy anterior a 1550.

Nos encontramos ante una construcción plenamente aislada de geometría cúbica, autosuficiente y ordenada de un modo racional en virtud de un solemne patio central. Bien podríamos decir que en este caso ${ }^{18}$ ya ha triunfado plenamente la

17 Ibidem, pág. 120.

18 Vandelvira invierte la superposición vitruviana de los órdenes arquitectónicos, diseñando para su primer cuerpo pilastras corintias, jónicas para el segundo, y alternancia de cariátides y telamónes en su cuerpo ático, posiblemente inspirados estos soportes antropomórficos en la edición vitruviana de Césare Cesariano de 1521, aunque los modelos a imitar, tal vez, estén sacados de la obra de Piero Apianus, "Inscriptiones Sacrosanctae". En cualquier caso -como ha señalado el Prof. Delfín Rodríguez-nunca podremos ignorar la presencia de modelos franceses $y$, de un modo muy particular, las influencias directas de Du Cerceau. Rodriguez, D: "Andrés de Vandelvira y después. Modelos periféricos en Andaiucia. De Francesco Colonna a Du Cerceau». En Ubeda en el siglo xVI. Op. cit., págs. 321-369. 
configuración brunelleschiana de la residencia palaciega urbana, una configuración fortalecida por la inspiración albertiana que, en el ejemplo que nos ocupa, se visualiza en la conformación vertical, en función de pilastras, de los horizontales cuerpos de su fachada. $Y$ no es menos lo anteriormente dicho si pensamos que Andrés de Vandelvira, de manera un tanto ingenua, se inspira directamente en el «Modelo de casa romana» de la edición vitruviana de Fra Giocondo de 1511.

Vandelvira, siguiendo los precarios grabados de este texto latino, articula de un modo intiutivo y experimentalista toda una gran fachada, cuyo referente más próximo habría que buscarlo en la arquitectura italiana del Quatrocento.

Esta fachada, expresión de la ordenación interna del edificio, de desarrolla de manera coherente en tres cuerpos, ordenados en virtud de pilastras y soportes antropomórficos, cuya configuración canónica es alterada por el maestro de Alcaráz, ejerciendo una interpretación tan libre como creativa de los postulados vitruvianos.

La planta del edificio, prácticamente un cuadrado regular, también responde de un modo básico a la propuesta de Fra Giocondo para casa romana. Sin embargo, si analizamos el trazado en planta del palacio ubetense, observamos un cierto des-

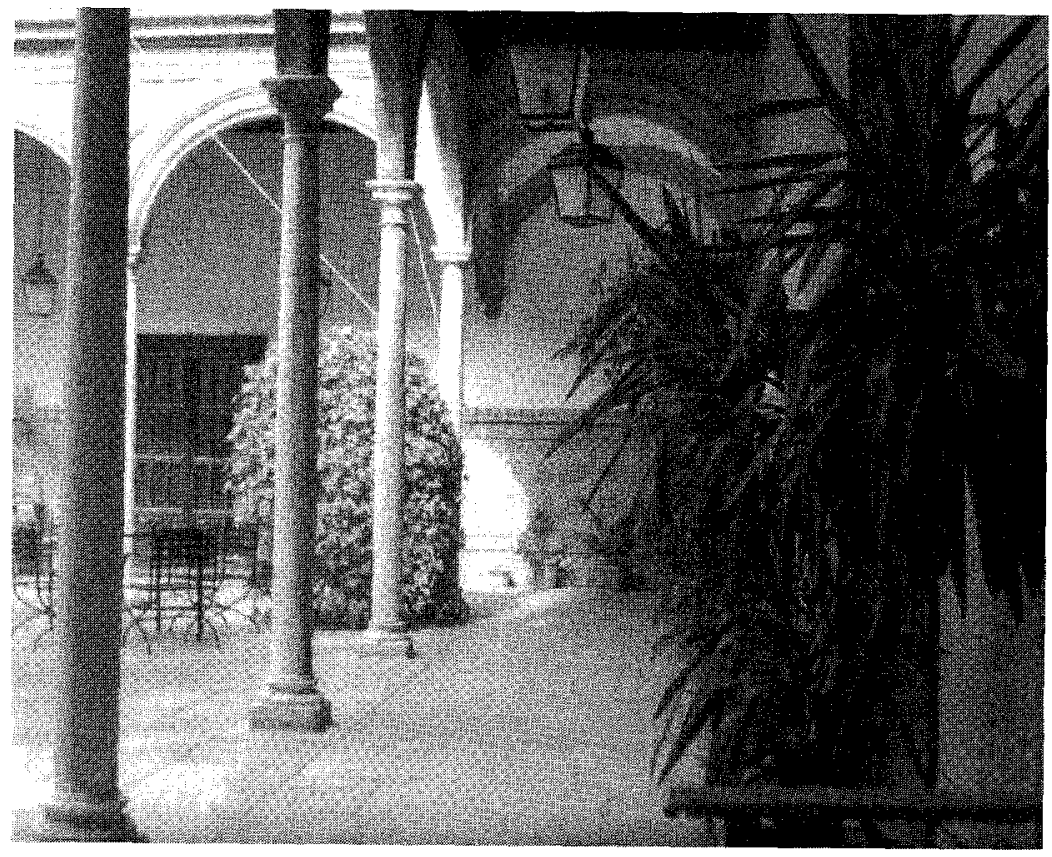

Fig. 7. Palacio de Deán Ortega. Detalle del patio. 
plazamiento del patio hacia su lado derecho, ensanchando la crujía izquierda para dar cabida a su escalera de doble tramo y estableciendo una gran «cuadra» cuadrada, donde una robusta columna central vertebra su sistema de cubrición en función de bóvedas baídas.

Este espacio pensamos - y es una mera hipótesis-, dado el grosor de sus muros, debió ser planeado como la base de una torre que, al igual que en el palacio de Francisco de los Cobos, podría haber sido ideada para su ubicación en la trasera de la edificación. Sin duda alguna, si pudiéramos confirmar este supuesto, nos encontrariamos ante un ejemplo más de focalización emblemática del edificio hacia el otro espacio urbano del que era lindero, la calle Real -en un cruce de calles con la actual calleja del Sagrado Corazón-, principal arteria de la ciudad ${ }^{19}$.

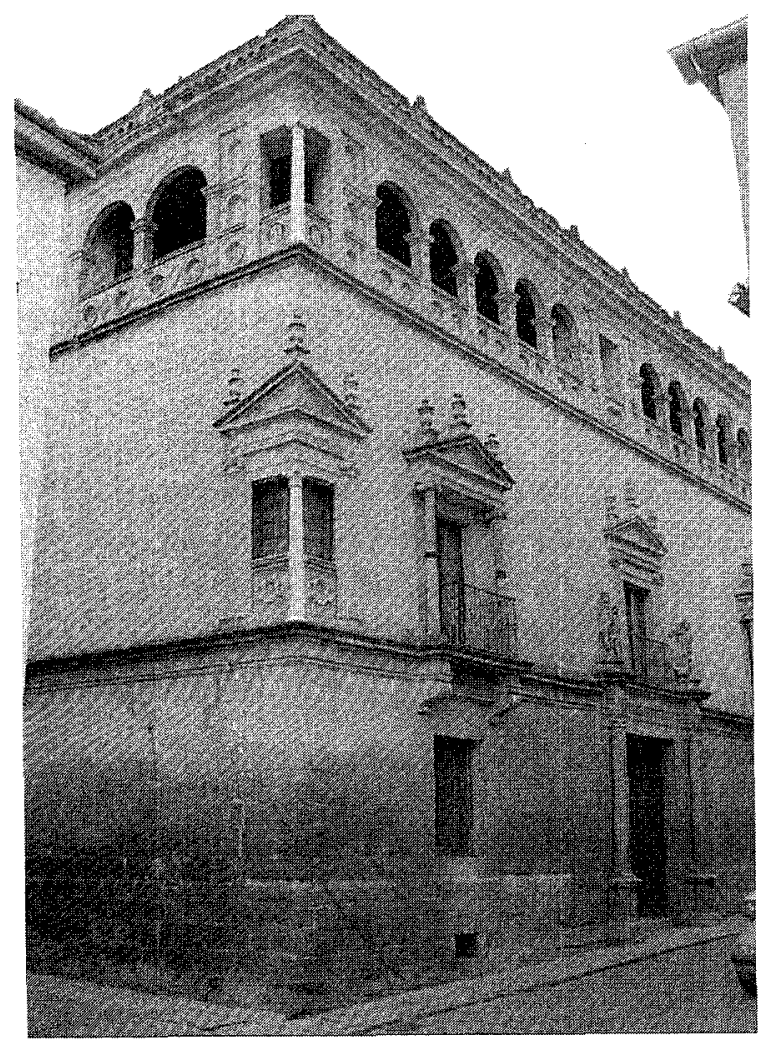

Fig. 8. Palacio Vela de los Cobos.

19 Hay que hacer notar que la actual Plaza del Ayuntamiento fue abierta en el siglo xix, pues de hecho su espacio constituía el jardín o huerto trasero del palacio de don Juan Vázquez. 
$Y$, desde luego, si nuestra tesis fuera confirmada, nos encontrariamos ante un elocuente fenómeno de yuxtaposición conceptual y convivencia tipológica: un palacio que se concibe como unidad autosuficiente en su espléndida fachada hacia el espacio abierto del «Llano de santa María» y que, por otra parte, conserva la pervivencia del modelo de alcázar torreado hacia el otro espacio público al que se proyecta, la angosta y prolongada calle Real, uno de los dos accesos que, por aquel entonces, mantenía la gran plaza con la ciudad.

La focalización pretendida de este torreón, o lo que es igual, el intento de captación simbólica de una perpectiva visual en la ordenación espacial de este principal viario, iba a ofrecer otros hermosos ejemplos en la ciudad.

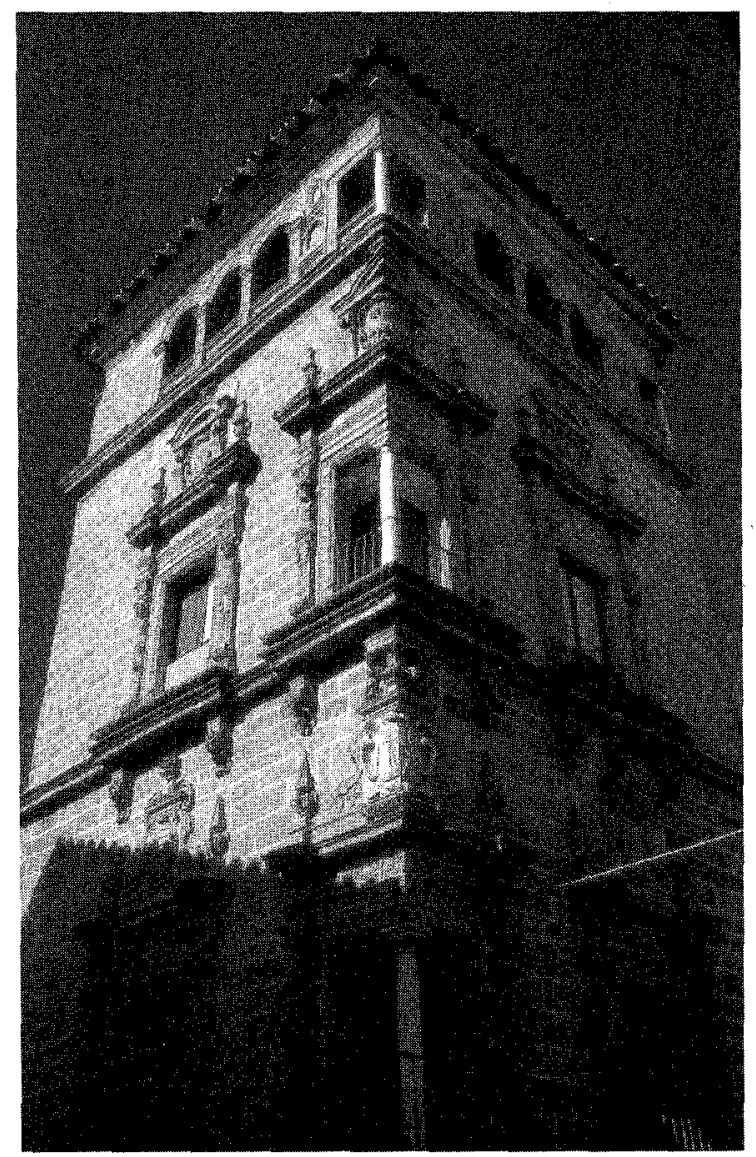

Fig. 9. Palacio del Conde de Guadiana. 
No hay que ignorar que, junto a otras mansiones torreadas que analizaremos más adelante, en Úbeda, el tema de otra edificación civil privada diseñada con torre angular, luego no ejecutada, se volvería a plantear en el último cuarto de siglo con el PALACIO DE LOS BUSIANOS, mandado labrar por el caballero Santiaguista Diego López Messia.

El patio de esta hermosa residencia había sido contratado en 1581 por los canteros Diego Gil y Diego de Avila, con la expresa condición de atenerse en todo momento al modelo ya ejecutado por Vandelvira en el Hospital de Santiago ${ }^{20}$. Este dato nos brinda la única coordenada cronológica de que disponemos para fechar el resto de su construcción.

No obstante, parece ser que la fachada debió ser iniciada con anterioridad. Esta presenta dos "cuartos", el principal, de clara inspiración horizontal y una rigurosa ordenación simétrica, y el torreado, ideado en acodo como base de un futuro mirador que habría de instaurar un poderoso foco de visualidad en el mismo centro de la concurrida calle donde se ubica, la calle de la Trinidad, paso obligado de una de las principales salidas de la población, que en parte quedaría estrechada por el mismo. De haberse concluido, esta torre-mirador literalmente se hubiese «asomado» al centro de la misma calle, proyectando su silueta hacia la plaza de Toledo, uno de los núcleos neurálgicos y mercantiles de la ciudad.

La focalización, gracias al triunfo de las leyes de la perspectiva, sin cuya existencia es imposible la comprensión de tantos aspectos relacionados con las artes plásticas, la arquitectura y el urbanismo del Renacimiento, constituye un elementos de transcendental importancia a la hora de interpretar el significado de muchas de nuestras arquitectura en el contexto urbano donde son acogidas. Esta práctica arquitectónica, íntimamente ligada a la composición urbana del momento - tal como nos recuerda Marín de Terán- se vincula a las teorías del fín de la perpectiva y de la calle cerrada, "consistentes en la apropiación de visuales más o menos largas por parte de piezas o edificios con objeto de alcanzar una mayor presencia y protagonismo" ${ }^{21}$.

20 Moreno Mendoza: Úbeda... pág. 137.

21 Marín de Terán: Op. cit., pág. 180. El autor cita paradigmas de estos planteamientos como el arco de triunfo que corta la continuidad de la calle en una "escena urbana» dibujada por Cesariano, o la manera en que San Giovanni dei Fiorentini tapona un extremo de la romana via Paolina. 


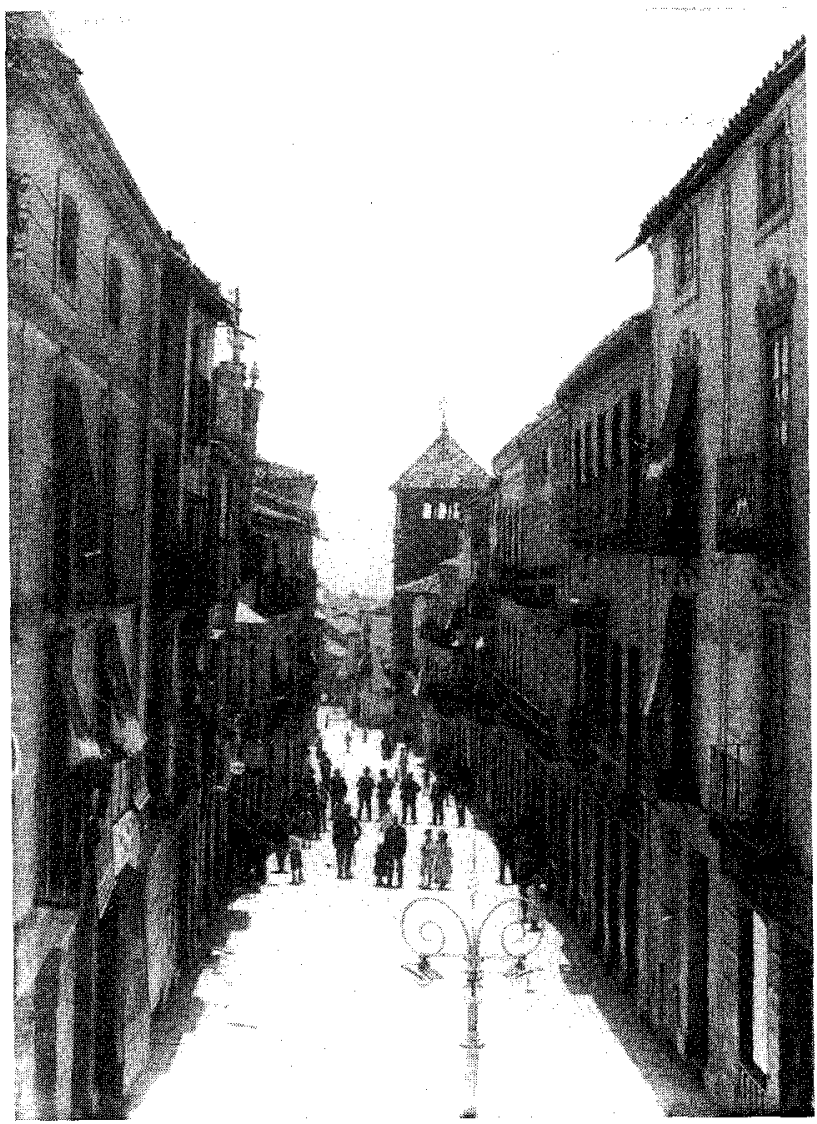

Fig. 10. Calle Real. Al fondo Torre de Conde de Guadiana (c. 1900).

\section{LA SEGUNDA MITAD DEL SIGLO: LOS PALACIOS VELA DE LOS COBOS Y MARQUES DE LA RAMBLA}

El palacio mandado construir por don Francisco Vela de los Cobos, otro ilustre miembro del linaje Cobos-Molína, aporta a la arquitectura ubetense del siglo, como primera novedad, la galería superior de su tercer cuerpo proyectada en fachada, un ingrediente claramente emparentado con otros modelos hispanos como apreciamos en los palacios salmantinos de Fonseca y Monterrey, o el zaragozano de Luna, cuyas condiciones son dictadas en 1561 al cantero local Jorge Leal.

En este documento notarial, Leal «se hobliga a hazer los arcos de la galeria conforme a la traza y condiciones por precio de noventa ducados estos arcos 
con sus miembros y ventanas de la delantera y testero del quarto del Real y por las molduras del arquitrabe y friso y cornisa de encima de los arcos...» ${ }^{22}$.

El texto, curiosamente, presenta en su marginalia unos esquemáticos dibujos explicativos, realizados por su tracista, Andrés de Vandelvira.

La fachada del palacio, compacta y menos articulada que las anteriores, queda organizada en tres plantas de marcada horizontalidad.

Sin embargo, junto a la galería superior, el elemento que más sobresale en su trazado es el de las ventalas en ángulo, ventanas «a dos hazes», que el maestro introduce con cierta insistencia.

Este modelo de vano en esquina, con parteluz de columna de mármol, ya había sido ensayado en la fachada del palacio del deán Ortega, inagurandose un prototipo tipológico de gran éxito en la ciudad y su ámbito comarcal de influencia.

Obviamente la ventana en ángulo no es privativa de la arquitectura civil del Quinientos en Úbeda. Este elemento, que llega a configurar la arquitectura de toda una época, podemos calificarlo como propiamente hispano

Paloma del Hoyo, en un artículo publicado en 1976, ya se refería al papel jugado por estas ventanas en ángulo en el Renacimiento español, señalando dos centros que constituyen sus principales focos de difusión: Ciudad Rodrigo y la provincia de Cáceres, fundamentalmente su capital y Trujillo ${ }^{23}$.

También, la autora de este trabajo, hacía especial hincapié en algo muy interesante: la vinculación de este elemento morfológico a la arquitectura civil de ámbito privado erigida por una pequeña y mediana nobleza.

Para nosotros, de nuevo, el principal valor que estos balcones angulares, estas aristas de esquina, nos ofrecen es su original configuración retórica como elemento de focalización visual del edificio. Y esta vez, como no podría ser de otro modo, hacia la calle Real y en un nuevo cruce de callejuelas

Abierto a una placeta, en realidad el típico espacio libre situado ante una puerta de muralla, espacio tal vez ampliado que preside, se encuentra el PALACIO del MaRQués de LA RAMBLA.

Esta mansión señorial, en realidad, había sido fundada por don Francisco de Molina y Valencia, miembro de la familia de los Cobos-Molína, regidor de la ciudad y capitán de infantería en la sublevación de los moriscos granadinos.

22 Moreno mendoza: Úbeda..., pág. 129.

${ }^{23}$ Hoyo y Alonso-Martínez, P.: "Las ventanas de ángulo del Renacimiento Español». Goya, num. 130, enero-febrero, 1976 


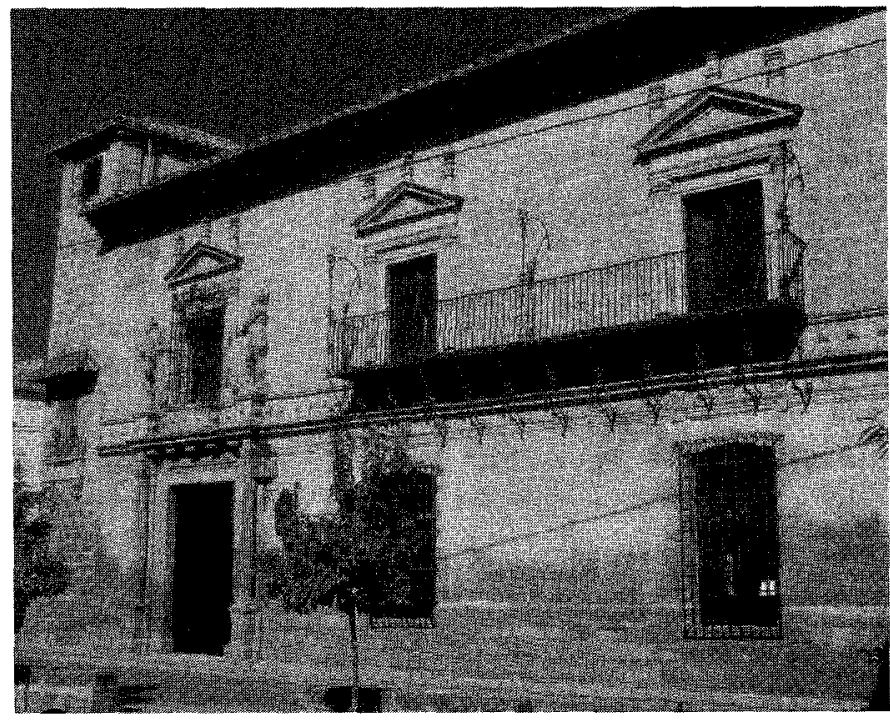

Fig. 11.

Casado con doña Leonor de los Cobos (era por tanto cuñado de Vela de los Cobos), en 1575 contrata con los canteros locales Juan de Madrid, Juan Hernández y su hijo Cristobal, la labra de sus sillares para la labra de la fachada de su casa, sita en el portillo de la Calancha. Ese mismo día, su promotor se concierta con los Hernández, al objeto de que estos ejecuten «una portada e ventana encima», la cual habría de mantener la "forma e manera de la portada e ventana que esta fecha en las casas principales de Francisco vela de los Cobos, difunto, en Santo Domingo; la qual dicha portada a de ser de el tamaño e de altura e largura que la dicha portada e ventana tiene; e las piedras para hazer los salvajes y escudos an de ser del tamaño e medida que vos me dieredes... ${ }^{24}$.

Las semejanzas formales entre las fachadas de ambos palacios no son gratuitas, reproduciendose en este caso un fenómeno frecuente en la arquitectura local de este siglo, cual es la repetición mimética de modelos arquitectónicos bien identificados por expresa voluntad del comitente ${ }^{25}$.

24 Moreno mendoza: Úbeda..., pág. 131.

25 No habría de ser este el único caso pues, junto a la portada de la Torre del tesorero que veremos a continuación, aparecen otros ejemplos en los protocolos notariales como el suscrito por don Rodrigo de Biedma Porcel, en 1612, con el cantero Juan Diego de Godoy, para la realización de todas las molduras de la puerta y ventana de las casas principales del primero, «a semejanza de las del palacio de Vela de los Cobos». AlmAGro Garcia, A: Artistas y artesanos en la ciudad de Úbeda durante el siglo XVII. Jaén: Universidad, 2003, pág. 173. 
Las condiciones de obra de este palacio son dictadas en noviembre de 1575, cuando Andrés de Vandelvira ya ha fallecido en Jaén. Pero poco importa, si sus esquemas compositivos van a seguir siendo reutilizados de un modo reiterativo por los maestros canteros instalados en la ciudad.

En cualquier caso, si que apreciamos una clara regresión en la racionalidad orgánica del proceso constructivo de estas "casas principales". Desconocemos en que momento edilicio se encontraba el resto de la construcción, más, en lo que a la fachada se refiere, sabemos que, en primer lugar, son encargados sus sillares «al pie de la obra», para luego, de manera, absolutamente suscinta, ordenar un proyecto de portada como elemento aislado en el conjunto global de la fachada, lo que constituye todo un ejemplo esclarecedor del modo de operar en la arquitectura local de estas décadas, a veces fragmentario y, casi siempre, sujeto a procesos de ejecución lentos y raramente unitarios.

La fachada resultante presenta dos cuerpos separados por impostas de punta de diamante.

De marcado diseño horizontal, en el inferior se abre la portada, desplazada por completo a su lado izquierdo. Esta, adintelada, queda enmarcada por exentas columnas corintias y retropilastras. Unos vanos rectangulares - de dimensiones originales más reducidas-, con sencilla rejería, completan este cuerpo sobre un zólalo rematado en bocel.

Su segunda planta esta compuesta por huecos más amplios o balcones, formados por pilastras jónicas (nueva inversión de los órdenes clásicos), entablamento y frontispicio triangular con modillón o «espejo» en su tímpano y acróteras en los vértices. El vano correspondiente a la portada, esta vez en forma de ventana con espléndida rejería, queda escoltado por magníficos tenantes de un vigoroso modelado, que portan las armas de los Molina y Valencia y de los Vela y Cobos. Son estos, por tanto, los "salvajes" que veíamos en las condiciones, dos robustos y barbados soldados vestidos a la romana, mucho más imponentes, en su tamaño y expresión, que los que presiden el palacio Vela de los Cobos, que apenas son delicados infantes.

Culmina la fachada una volada cornisa compuesta por ménsulas de acanto y mascarones.

\section{DE VUELTA AL BALUARTE SEÑORIAL: LA TORRE DEL TESORERO}

Esta mansión solariega había sido construida por dos nuevos miembros del linaje Molína, los hermanos Lope Molína Valenzuela y Hernando de Herrera, ambos canónigos de la Iglesia Mayor Colegial de Santa María. Adquirida años más tarde 
por don Pedro de Toledo, primer marqués de Mancera, el edificio consolidaría el nombre de PALACIO DE MANCERA, por el que es conocido en la actualidad.

Ignoramos la fecha precisa de su construcción y el único dato cronológico de que disponemos es muy tardio, 1637, remitiendonos a los reparos de la torre, "ya que la fabrica amenazaba ruina» 26 .

El edificio se ordena en torno a un pequeño patio adintelado, con balaustres de madera y zapatas alcarreñas, estableciendo un prototipo ajeno a la tradición local de arcos de medio punto sobre columnas marmóreas. Su organización en dos plantas proyecta una única y horizontal fachada, rematada en su extremo norte por un segundo cuerpo, o torre-mirador, desarticulado del resto de la fachada.

Dividida en dos pisos por una sencilla cornisa, en su primero se establece la portada, nuevamente un trasunto literal del modelo inagurado por Vandelvira en el palacio Vela de los Cobos. En el segundo, y sin el más mínimo rigor en sus aspiraciones de simetría, vemos una hermosa ventana con rejería, de columnas y retropilastra toscanas, coronadas por entablamento y frontis partido, siguiendo una composición ya netamente barroca.

El aparato decorativo está centrado esencialmente en su torre que, metonímicamente, da nombre y define al palacio.

Éste nos brinda un variado repertorio de temas profanos y religiosos de diversa procedencia y decadente ejecución.

En su segundo piso, siguiendo la línea divisoria genera de la fachada, encontramos dos nuevas ventanas adinteladas con rejería, rematadas por cornisa apeada sobre ménsulas de decoración geométrica. Sobre la ventana de poniente, distinguimos un altorrelieve con la figura de un Niño Jesús abrazado a su cruz, acompañados por ángeles, o putti desnudos, recostados sobre una calavera. Esta no es más que una tradicional representación del Eros y Thanatos cristianizado, el amor y la muerte de la que nace la resurrección, una versión primitiva del "Cristo Niño de Pasión».

Por el contrario, en su ventana norte, la decoración en relieve es meramente ornamental: mascarones femeninos a modo de canéforas y sirenas entrelazadas - a manera de tenantes-, cuyo origen francés se remontaría a los primeros años del siglo.

Ya en el tercer cuerpo de ésta, independiente de la organización horizontal de la fachada, lo que vamos a vislumbrar en la ornamentación de una de sus ventanas son estípites antropomórficas, que nos recuerdan modelos convencionales tar-

26 Almagro Molina: Op. cit., pág. 277. 
dorenacentistas, ya ensayados en portadas de libros y otros soportes impresos ${ }^{27}$, sin que por ello tengamos que dejar de remitirnos a fuentes más profesionales de origen flamenco, como la obra de Jan Vredeman de Vries (Amberes, 1565).

\section{Un colofón espléndido: el palacio del Conde de Guadiana.}

El palacio del Conde de Guadiana había sido rebautizado por don Lope de la Cueva y Guzmán, nombrado primer conde de Guadiana en 1711 por Felipe V.

En realidad, su origen tendría que remontarse a Martín Alfonso de Ortega quien, en 1487, había comprado en la collación de San Pedro una casa, sin duda alguna la primera de una larga serie de adquisiciones, para la construcción de su morada. Serían, por tanto, los Ortega Porcel y Ortega Messia, descendientes de don Martín, los verdaderos ejecutores de esta señorial mansión ${ }^{28}$.

La residencia y solar familiar de uno de los más prestigiosos linajes de la ciudad estaría plenamente consolidada en 1560, año en que en que ya figuran «unas casas principales en la collación de san Pedro» en la relación de bienes vinculados al mayorazgo recientemente creado por la familia.

Gracias a los trabajos publicados por Almagro García sobre los protocolos notariales ubetenses del siglo XVII, podemos documentar de un modo satisfactorio tanto la evolución cronológica, como los autores que intervienen en esta fábrica.

La noticia más antigua data de 1600 , cuando es tasada «la portada delantera e valcones desde el prinçipio de los fundamentos e zimientos hasta la cornixa questá asentada sobre que carga el primero suelo con toda la portada como de presente está» ${ }^{29}$. Los trabajos de este primer cuerpo del palacio habían corrido a cargo de $\mathrm{Pe}$ dro del Cabo «el Viejo», un maestro en cantería seguidor de la estela vandelviriana.

Ni qué decir tiene que nos estamos refiriendo al cuerpo principal de la mansión, mandada construir por don Antonio de Ortega y Porcel. Y, por supuesto, estamos hablando de un palacio de neta concepción cúbica, abierto a una pequeña plaza, que proyecta al exterior dos fachadas de semejante composición, donde distinguimos ventanales de molduras en acodo, $u$ orejas salientes, coronados por frontis triangulares partidos y apeados sobre ménsulas.

Más noticias sobre la edificación surgen en 1612 cuando es contratado el patio de la casa por el cantero Francisco de Herrera «el Viejo», quien se comprome-

\footnotetext{
27 La edición de la Arcadia de Lope, de 1598, sería uno de los tantos ejemplos válidos.

28 Toral Peñaranda, E.: Historia del linaje de Ortega, Úbeda, 1953.

29 Almagro García.: Op. cit., pág. 137.
} 


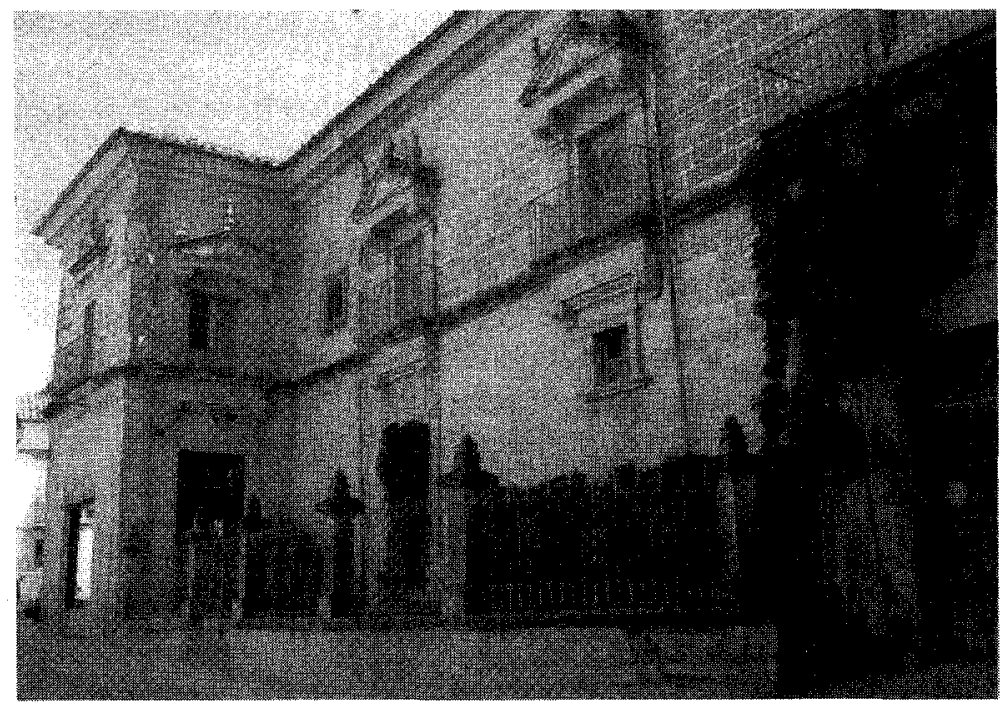

Fig. 12. Palacio de los Condes de Busianos.

tía a instalar «...bentiseis columnas de marmol blanco de las canteras de filabres y acabadas, bruñidas, puestas con todas sus guarniçiones de basas y capiteles y dieciseis repisas para. las paredes do cargan los mobimientos de los arcos..." ${ }^{30}$.

Muy avanzada la fábrica del cuerpo residencial, tras la ardua y dilatada tarea de adquirir un total de cuatro casas en la calle Real, le llega el turno a su suntuosa torre.

En 1611 el maestro en cantería Pedro de Alarcos, en compañía de Juan de Anguís, concertaban con Ortega Porcel la entrega de todos los sillares vivos y aceras francas y vivas necesarios para la obra de sus casas principales. Un año más tarde Francisco de Herrera "el Viejo" hacía entrega de la cuatro columnas destinadas a parteluz de los balcones en doble haz diseñados para la torre, al tiempocuriosamente- que mantenía un litigio con el promotor sobre la idoneidad de los mármoles encargados para el patio, que habían sido rechazados por no ajustarse a las condiciones pactadas.

Finalmente, en 1614, Alarcos y Anguís se comprometen con don Antonio Ortega Porcel a realizar a destajo la galería alta de la torre, que habría de ser «...en redondo desde ençima de la cornisa que corre en redondo de la dicha torre y de la forma y hechura y altura de la galeria que tiene en sus casas don Pedro Bela de

30 Ibidem, pág. 188. 
los Cobos..., y con las mismas molduras cornijas antepechos y toda la demás obra puntualmente como está la galería de las casas del dicho don Pedro... ${ }^{31}$.

Un último dato nos vendría suministrado en 1615 cuando el promotor encarga al maestro cerrajero Nicolás Pérez 11 balcones de hierro labrados y cincelados, de los cuales seis habrían de ser para la torre, "y ni más ni mensos se an de haçer las cornijas conforme a las que tiene don Pedro de los Cobos en los falcones de la delantera de su casa...” 32 .

Todas estas noticias nos inducen a pensar que, aunque la construcción de esta mansión fuera iniciada por su cuerpo residencial, la fábrica en su conjunto era planeada y trazada, de manera unitaria, muy a finales del anterior siglo, para desarrollarse en los 15 primeros años del XVII.

La torre consta de cuatro cuerpos.

El primero es una mera continuidad del cuerpo inferior del palacio. Mas el segundo, como los restantes, está formado por tres grandes vanos, siendo el central en ángulo. Su ornamentación es similar en todos: columna toscana de marmol blanco a manera de mainel en la ventana esquinada, estípites antropomórficas, corintias con pie vegetalizado, moldura de soga o funículo y entablamento con friso de decoración vegetal -muy geometrizada y esquemática-, al que se le añade moldura de tacos y la correspondiente cornisa. Sobre ésta, y a modo de edículos, encontraremos los magníficos escudos sobre filacteria.

En el tercer cuerpo las estípites femeninas han sido sustituidas por hermes; tambien el orden, esta vez jónico, que de nuevo es invertido.

Por fín, el cuerpo ático o mirador, absolutamente tradicional, es -como hemos podido apreciar- un mero remedo de la composición de Vandelvira para el palacio Vela de los Cobos.

La torre, desplazada a la calle Real, ubicada en un apéndice del palacio, como si de un anexo se tratara ajeno por completo al desarrollo orgánico del cuerpo cúbico residencial, constituye el mejor y más emblemático paradigma de focalización visual de cuanta arquitectura hemos visto en la ciudad.

El magnífico desarrollo de su aparato decorativo, donde se combinan elementos vernáculos como su galería superior, o el uso ya tradicional de ventanas "de doble haz", con ingredientes innovadores y netamente foráneos, de origen flamenco y transmisión culta -es más que probable que la decoración antropomórfica sea un prestamo literal de Vredeman de Vries, aunque a través de las ilustra-

\footnotetext{
31 Ibidem, pág. 103.

32 Ibidem, pág. 259.
} 
ciones de Samuel Marolois ${ }^{33}$-, no oculta su principal función propagandística y ostentosa, que no es otra que el verdadero despliegue de todo un árbol genealógico familiar. Un manifiesto contundente, de talante nobiliario, exponente de la turbulenta personalidad de su comitente, hombre arrogante y violento, del que tenemos -a través del testamento paterno- sobradas muestras de su bizarro carácter.

\section{A MODO DE CONCLUSION}

Como hemos podido ir comprobando a lo largo de este estudio, no podemos decir que exista en la ciudad un desarrollo tipológico de su mansión señorial acorde con planteamientos estilísticos evolutivos de conformidad con la implantación, cada vez más arraigada, de los nuevos lenguajes clasicistas.

La pervivencia de elementos que responden a una tradición mudejar, o el arraigo de constantes arquitectónicas medievales, son factores que conviven, en algunos casos, con planteamientos de una modernidad conceptual y lingüística asombrosa. Este sería el caso del palacio Vázquez de Molína, donde la ambivalencia de formulaciones tipológicas y la versatilidad de concepciones espaciales es bien expresiva.

El prototipo de alcázar-urbano que inaguraba la Casa de las Torres, con su hosco aspecto castrense, perdurará a lo largo del siglo, permutando la impronta defensiva de sus torres por un modelo consolidado, y hasta codificado, de torre-mirador, dotado de valores simbólicos señoriales y una fuerte vocación por dotar al escenario urbanos de claros referente de jerarquización visual, en una ciudad donde el urbanismo - y ello a pesar de las diferentes reformas urbanas llevadas a cabo a lo largo del siglo- continuaba siendo de configuración medieval.

33 MAROLOIS, S.: Architectura et perspectiva ac practica opus notis ilustrarum per Samuelen Marolois. Amsterdam, 1568, Libro de Joannis Vredemannis frissi. 
